\title{
Efeito da granulometria do milho sobre a qualidade do extrusado de dietas para papagaio-verdadeiro (Amazona aestiva)
}

MORENO, Tatiane ${ }^{1 ;}$ MERCHIORI Aline ${ }^{2}$; WERNECK, Gabriel ${ }^{3}$; ROCHA, Chayane ${ }^{4} ;$ FÉLIX Ananda $^{4}$

1 Zootecnista, Mestranda do Programa de Pós-graduação em Zootecnia - UFPR

2 Graduanda em Medicina Veterinária - UFPR

${ }^{3}$ Msc. Zootecnista. Parque Zoológico Municipal Quinzinho de Barros - Sorocaba

${ }^{4}$ Professora Dra, Departamento de Zootecnia - UFPR

E-mail: tatiane.t12@gmail.com

RESUMO: Objetivou-se analisar os efeitos da granulometria do milho sobre a qualidade do extrusado em dietas para papagaio-verdadeiro (Amazona aestiva). Para tanto, o milho com inclusão de aproximadamente $74 \%$, foi moído em moinho de martelos em peneiras de 0,8;1,2; 2,6 e 4,2 mm e, as demais matérias-primas foram moídas em peneira com tamanho de furo de $0,8 \mathrm{~mm}$. Em seguida, as dietas foram extrusadas, com um tamanho de extrusado de $4 \mathrm{~mm}$, gerando quatro tratamentos de diferentes granulometrias: $528,575,628$ e 830,5 $\mu \mathrm{m}$ de diâmetro geométrico médio (DGM). Foram realizadas análises de densidade, tamanho, dureza e porosidade dos extrusados. Os dados foram submetidos à análise de regressão. Dietas com maiores DGM resultaram em aumento linear $(P<0,05)$ da densidade. As demais variáveis de qualidade do extrusado não foram afetadas pela granulometria do milho $(P>0,05)$. A qualidade dos extrusados é mantida mesmo com moagens mais grosseiras, demonstrando que o DGM do milho interfere na densidade da dieta, mas não influencia no tamanho e na dureza dos extrusados.

Palavras-chave: diâmetro geométrico médio; DGM; psitacídeos; ração.

\section{INTRODUÇÃO}

A granulometria é um método de análise que visa classificar as partículas de uma amostra pelos respectivos tamanhos e medir as frações correspondentes a cada tamanho. $\mathrm{Na}$ nutrição de aves, sua determinação é importante, pois o tamanho, a forma e as estrutura das partículas de uma dieta influenciam diretamente sobre a digestibilidade dos nutrientes, a dispersibilidade dos nutrientes na massa da dieta, a densidade da mesma, na qualidade dos extrusados, no transporte (formação de finos) e na energia consumida na moagem. A granulometria é medida após a moagem por meio do peneiramento dos ingredientes e dado pelo Diâmetro Geométrico Médio (DGM) expresso em $\mu \mathrm{m}$. Essa medida determina o tamanho e uniformidade das partículas dos ingredientes destinados à fabricação das rações (ZANOTTO e BELLAVER, 1996). A granulometria pode variar de muito fina a muito grossa, de acordo com o tamanho dos furos da peneira do moinho onde são processadas. A granulometria mais fina $(0,4-0,5 \mu \mathrm{m})$ aumenta a digestibilidade da dieta em mamíferos, pois partículas menores são 
mais facilmente envolvidas pelo suco digestório, favorecendo assim a ação das enzimas sobre os ingredientes e facilitando a digestão de nutrientes. Entretanto, estudos com frangos de corte demonstram que partículas mais grossas (acima de 0,8 $\mu \mathrm{m}$ ) estimulam a contração da moela, permitindo maior tempo de retenção da digesta no trato e consequentemente maior tempo de ação enzimática sobre os nutrientes (NIR et al. 1994; RIBEIRO et al. 2002).

Em relação ao processamento das dietas, partículas mais finas favorecem o manuseio e as características de mistura da ração e a extrusão. Porém, o gasto de energia na fábrica é maior quando comparada com partículas moídas mais grosseiramente, as quais resultam em maior economia com energia e maior eficiência (toneladas/hora) de moagem. Ainda, por reduzir a eficiência do processo de extrusão, é possível que partículas moídas mais grossas influenciem negativamente na qualidade do extrusado formado. Embora haja estudos sobre o efeito da granulometria da dieta em frangos de corte, não foram encontrados trabalhos que avaliassem esse efeito em dietas extrusadas para psitacídeos. Desta forma, é essencial identificar a granulometria mais adequada a ser utilizada na dieta dessas aves, podendo assim proporcionar o melhor aproveitamento dos nutrientes, associado à redução dos gastos com energia elétrica, aumento no rendimento de moagem e qualidade do extrusado.

Assim, objetivou-se avaliar o efeito da granulometria do milho sobre as características do extrusado de dietas para papagaio-verdadeiro $(A$. aestiva).

\section{MATERIAL E MÉTODOS}

As dietas foram formuladas segundo as recomendações da AAFCO
(1998) para a Ordem dos Psittaciformes. As matérias-primas utilizadas nas dietas foram cedidas, moídas e extrusadas pela empresa Biotron Zootécnica ${ }^{\circledR}$. O milho utilizado nas dietas, com inclusão de aproximadamente de $74 \%$, passou pelo processo de moagem em moinho de martelos utilizando-se peneiras com quatro diferentes tamanhos de furos $(0,8 ; 1,2 ; 2,6$ e $4,2 \mathrm{~mm})$. As demais matérias-primas foram moídas em peneira com tamanho de furo de 0,8 $\mathrm{mm}$. Após essas moagens separadas, foi realizada a mistura de todas as matérias-primas de cada dieta experimental que em seguida, foram extrusadas com tamanho de $4 \mathrm{~mm}$. As dietas extrusadas experimentais foram expressas segundo o DGM obtido após as moagens do milho: 528, 575, 628 e 830,5 $\mu \mathrm{m}$.

A densidade foi obtida pela relação massa/volume em três amostras de cada tratamento. O tamanho dos extrusado foi mensurado em paquímetro digital em 50 amostras de cada tratamento. A dureza foi obtida pelo durômetro (Ethik Techonology 298 DGP) expresso em kgf, em 20 amostras de cada tratamento. Foi realizada microscopia eletrônica de varredura com aumento de 40X em todas as dietas para verificar a porosidade dos extrusados. A densidade, tamanho e a dureza foram analisadas quanto a normalidade pelo teste de Shapiro-Wilk e submetidas à análise de regressão $(\mathrm{P}<0,05)$. A porosidade foi apresentada de modo descritivo.

\section{RESULTADOS E DISCUSSÃo}

Observou-se que a densidade dos extrusados aumentou linearmente com o aumento do DGM do milho $(P<0,05)$ enquanto as demais variáveis não diferiram estatisticamente $(P>0,05)$ (Tabela 1). Apesar da maior densidade e menor área de porosidade, os parâmetros de tamanho e dureza não 
foram afetados, indicando que a qualidade dos extrusados foi mantida mesmo em moagens mais grosseiras.

\begin{tabular}{|c|c|c|c|}
\hline $\mathrm{DGM}(\mu \mathrm{m})$ & Tamanho $(\mathrm{mm})$ & Densidade (g/l) & Dureza (kgf) \\
\hline 528 & 0,71 & 420 & 4,07 \\
\hline 575 & 0,67 & 480 & 3,13 \\
\hline 628 & 0,69 & 530 & 3,40 \\
\hline 830,5 & 0,70 & 510 & 3,80 \\
\hline$P$ linear & 0,684 & 0,021 & 0,717 \\
\hline $\mathrm{P}$ quadrático & 0,567 & 0,087 & 0,823 \\
\hline
\end{tabular}

Dietas com densidade alta são indícios de produtos pouco expandidos, com gelatinização do amido inadequada e com menor aproveitamento dos nutrientes (CAMIRE, 2000). No entanto para aves, a baixa gelatinização do amido não é um problema, uma vez que partículas maiores tendem a ficar retidas mais tempo no trato gastrointestinal, aumentando 0 aproveitamento dos nutrientes. Loureiro et al. (2013) não verificaram efeito significativo no consumo, digestibilidade, energia metabolizável e parâmetros fecais em papagaios-verdadeiros recebendo dietas que foram moídas em peneiras com tamanhos de furos $0,5 \mathrm{~mm}$ e 2,0 $\mathrm{mm}$, correspondente a $289 \mu \mathrm{m}$ e $367 \mu \mathrm{m}$ de DGM.Visto que neste mesmo estudo, as aves apresentaram aproveitamento semelhante dos nutrientes e da energia da dieta, independente do grau de moagem utilizado é possível inferir que a moagem fina dos ingredientes tornase desnecessária.

Em dietas de 528 à $830,5 \mu \mathrm{m}$ de DGM verificou-se aumento na metabolizabilidade da matéria seca, proteína bruta e extrato etéreo, indicando que o maior tamanho de partículas resulta em menor taxa de passagem do alimento pelo trato gastrointestinal, aumentando o tempo de ação das enzimas digestivas sobre os nutrientes e sua absorção no intestino (WERNECK, 2016).

Observou-se que as dietas extrusadas com milho de maior DGM tem a tendência a apresentar menor área de porosidade (tabela 2).
Tabela 2 Área de porosidade de extrusados de dietas com diferente diâmetro geométrico médio (DGM) para papagaio-verdadeiro (Amazonas aestiva). DGM $(\mu \mathrm{m}) \quad$ Área de porosidade $(\%) \quad$ Área de porosidade $(\mathrm{mm})$ $\mathrm{DGM}(\mu \mathrm{m}) \quad$ Área de porosidade $(\%) \quad$ Área de porosid $\begin{array}{lll}528 & 7,19 & 5,32 \\ 575 & 7,62 & 5,82 \\ 628 & 5,70 & 3,90\end{array}$

O menor número de poros em dietas com maior DGM justifica a maior densidade dos extrusados. A estrutura porosa do extrusado depende da plasticidade da massa atrás da matriz da extrusora, cujo principal responsável é o amido. $\mathrm{O}$ aumento da densidade e a diminuição do número de poros indicam que a gelatinização do amido foi menor nos tratamentos com maior DGM do milho, o que poderia ter tornado 0 extrusado mais duro. Entretanto, o resultado de dureza não diferiu entre os tratamentos, confirmando que a maciez do extrusado se manteve igual em todas as dietas. Para psitacídeos, comumente as dietas são ofertadas uma vez ao dia e ficam disponíveis até o dia seguinte. É interessante que os produtos apresentem densidade maior e porosidade menor adsorvendo menos umidade, já que devido ao longo tempo de exposição da dieta ao ambiente, essas duas características em conjunto tendem a garantir a textura do alimento por mais tempo.

Do ponto de vista de produção de rações, quanto maior o tamanho das partículas dos ingredientes, maior a economia com energia e eficiência (toneladas/hora) de moagem da matéria-prima. A partir da moagem do milho, um aumento no DGM das partículas de 515 para $905 \mu \mathrm{m}$, representa um aumento de $166 \%$ no rendimento da moagem e uma redução de $62 \%$ no consumo de energia elétrica (ZANOTTO et al. 1999).

\section{CONCLUSÃO}

Dietas com maiores granulometrias do milho ocasionaram aumento linear da densidade da dieta 
sem influenciar o tamanho e na dureza dos extrusados. O uso de dietas com moagens mais grosseiras pode ser interessante para fábricas de rações, pois diminuem o custo de produção sem comprometer na qualidade dos produtos.

\section{REFERÊNCIAS}

AAFCO - Association of American Feed Control Officials, 2003. Dog and cat nutrient profiles. Official Publications of the Association of American Feed Control Officials Incorporated., Oxford, IN, USA.

CAMIRE, M.E. Chemical and nutritional changes in food during extrusion. In: RIAZ, M.N. Extruders in food applications. CRC Press, Boca Raton, p.127-147, 2000.

LOUREIRO, B.A.; PRADO, P. L.; BALLESTERO, M. C. M.; JUDICE MARIA, A.P.; SÁ, F. C; CARCIOFI, A.C. Granulometria dos ingredientes de alimento extrusado e digestibilidade e parâmetros fecais de papagaioverdadeiro (Amazona aestiva). In: V Congresso Internacional sobre nutrição de animais de estimação e XII Simpósio sobre nutrição de animais de estimação, 2013.

NIR, I.; SHEFET, Y.; ARONI, G. Effect of particle size on performance. I. corn. Poultry Science, 73: pg. 45-49, 1994.

RIBEIRO, A.M.L.; MAGRO, N.; PENZ, jr. A.M. Granulometria do milho em rações de crescimento de frangos de corte e seu efeito no desempenho e metabolismo. Revista Brasileira de Ciência Avícola, v. 4, n.1, p. 047-053, 2002.

ZANOTTO, D.L.; BELLAVER, C. Método de determinação da granulometria de ingredientes para uso em rações em suíno e aves. Concórdia: EMBRAPA-
CNPSA, 1996. 5p. EMBRAPA-CNPSA. (Comunicado Técnico, 215), 1996.

ZANOTTO, D.L.; GUIDONI, A.L.; BRUM, P.A.R. de. Granulometria do milho em rações fareladas para frangos de corte. In: REUNIÃO ANUAL DA SOCIEDADE BRASILEIRA DE ZOOTECNIA, 36, 1999, Porto Alegre, RS. Anais, SBZ, 1 CD-ROM, 1999.

WERNECK, G. R. Graus de moagem do milho em dietas extrusadas sobre a digestibilidade, palatabilidade e características fecais de papagaioverdadeiro (Amazona aestiva). Dissertação (Mestrado em Zootecnia) Universidade de Federal do Paraná, Curitiba. 2016.

Agradecemos ao apoio da Fundação Araucária e da Coordenação de Aperfeiçoamento de Pessoal de Nível Superior - CAPES na realização do $3^{\circ}$ Workshop de Nutrição de Animais Selvagens.
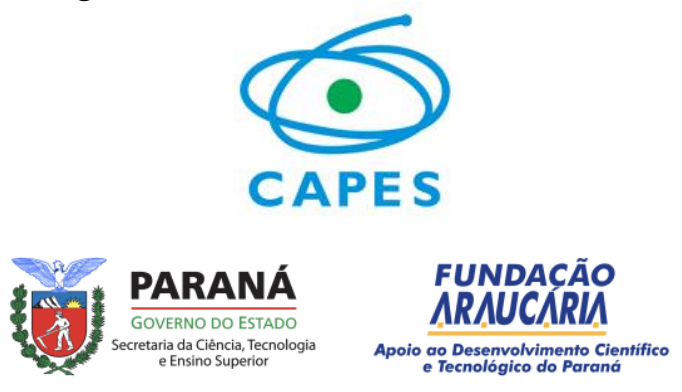